\title{
A global carbon and nitrogen isotope perspective on modern and ancient human diet
}

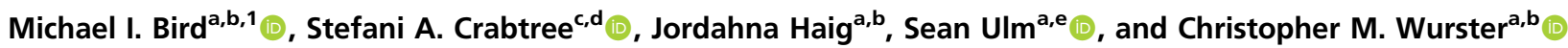 \\ ${ }^{a}$ Australian Research Council Centre of Excellence for Australian Biodiversity and Heritage, James Cook University, Cairns, QLD 4870, Australia; ${ }^{b}$ College of \\ Science and Engineering, James Cook University, Cairns, QLD 4870, Australia; 'Department of Environment and Society, Utah State University, Logan, UT

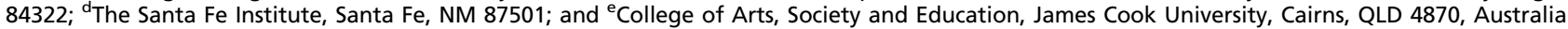

Edited by Thure E. Cerling, University of Utah, Salt Lake City, UT, and approved March 28, 2021 (received for review December 1, 2020)

\begin{abstract}
Stable carbon and nitrogen isotope analyses are widely used to infer diet and mobility in ancient and modern human populations, potentially providing a means to situate humans in global food webs. We collated 13,666 globally distributed analyses of ancient and modern human collagen and keratin samples. We converted all data to a common "Modern Diet Equivalent" reference frame to enable direct comparison among modern human diets, human diets prior to the advent of industrial agriculture, and the natural environment. This approach reveals a broad diet prior to industrialized agriculture and continued in modern subsistence populations, consistent with the human ability to consume opportunistically as extreme omnivores within complex natural food webs and across multiple trophic levels in every terrestrial and many marine ecosystems on the planet. In stark contrast, isotope dietary breadth across modern nonsubsistence populations has compressed by two-thirds as a result of the rise of industrialized agriculture and animal husbandry practices and the globalization of food distribution networks.
\end{abstract}

trophic | isotope | isoscape | diet

$\boldsymbol{H}_{\mathrm{n}}$ omo sapiens are the most widely distributed terrestrial mammal on the planet. Over the course of the Holocene, modern human range has extended to all continents, to the farthest islands of every ocean, and above the polar circles. The ability to rapidly adapt to newly encountered environments via technological and cultural innovation, that manifested ultimately in changes to our own genome, enabled this breath-taking range of expansion (1). Our capacity for successful innovation is tightly coupled to our ability to consume as "extreme opportunistic omnivores," that is, across multiple trophic levels, from the base of a food web to filling the niche of apex predator (2-4). The development of agriculture, animal husbandry, urbanized societies, and commercial trade progressively allowed us to engage in niche construction of increasing complexity and extent $(5,6)$. As we permanently extended our range to above the Antarctic Circle in the 20th century, we progressively extended our capacity for advanced ecosystem engineering, thereby achieving a high degree of control over the production and distribution of our food supply across the globe $(6,7)$.

The archaeological record documents our expansion into new habitats, our technological and social innovations, changing cultural practices, and the food that sustained us (8). While the physical remains of our diets, such as bones and charred plant remains, provide direct evidence of diet, not all foodstuffs are well-preserved. Moreover, such direct evidence does not indicate the proportion of different components that were consumed. A challenge in recreating past dietary components lies in accounting for taphonomic processes that may impact different dietary items at different rates, leading to underrepresentation of some important taxa (2). In contrast, the stable carbon and nitrogen isotope composition of human tissue (mostly collagen and keratin) has been investigated over the last several decades as a proxy for the proportions of different potential dietary components enabling an accounting for taphonomy (9). Carbon isotope composition $\left(\delta^{13} \mathrm{C}\right.$ value) provides an indication of relative contributions of aquatic and/or terrestrial sources of carbon in the diet. Nitrogen isotope composition $\left(\delta^{15} \mathrm{~N}\right.$ value $)$ is used to draw inferences regarding both the protein source and trophic level of an individual in the months or years before their death (10).

To date, studies involving patterns in the stable isotope composition of ancient human remains (mostly bone collagen that can be well-preserved) have tended to focus on regional-scale variations during the Holocene, with the intent of determining wholesale changes in subsistence strategies (e.g., agriculture and pastoralism) and changing technological innovation, as well as social practices and structures (11-13). Although interpretation can sometimes be straightforward when observed differences are large, smaller differences are complicated by the complexities associated with disentangling the ecosystem processes driving $\mathrm{C}$ and $\mathrm{N}$ isotope fractionation within the food webs supporting human diet $(13,14)$.

A parallel body of research has been conducted on the stable isotope composition of the tissues of contemporary humans (15-18). This research has mostly focused on noninvasive nail and hair keratin to examine the physiological processes in the human body, to deduce the recent movements of individuals (19), or to identify locations for repatriation of human remains (20). Substantial effort has been directed toward developing a spatial understanding of the controls on the stable isotope composition of

\section{Significance}

The carbon and nitrogen isotope composition of human tissues can be used to infer dietary information. We transformed isotope compositions of 13,666 modern and ancient analyses to make them comparable on a common scale. This reveals that the isotope dietary breadth of modern humans is highly compressed when compared to populations predating the development in 1910 of modern industrial fertilizer by the Haber-Bosch method. However, modern humans that still use "traditional" subsistence strategies retain remarkably similar isotope dietary breadth to all pre-Haber-Bosch human populations. Increased reliance on industrial agriculture and pastoralism is resulting in a cascade of "rewiring" to remaining food webs globally that can reduce the resilience of global ecosystems in the face of accelerating environmental change.

Author contributions: M.I.B. designed research; J.H. performed research; M.I.B., S.A.C., J.H., S.U., and C.M.W. analyzed data; and M.I.B., S.A.C., J.H., S.U., and C.M.W. wrote the paper.

The authors declare no competing interest.

This article is a PNAS Direct Submission.

This open access article is distributed under Creative Commons Attribution-NonCommercialNoDerivatives License 4.0 (CC BY-NC-ND).

${ }^{1}$ To whom correspondence may be addressed. Email: michael.bird@jcu.edu.au.

This article contains supporting information online at https://www.pnas.org/lookup/suppl/ doi:10.1073/pnas.2024642118/-/DCSupplemental.

Published May 3, 2021. 
modern human tissues, mostly as a consequence of the potential forensic application of this type of research $(18,21)$.

Archaeological and modern stable isotope results on human tissues are not readily comparable for multiple reasons (Materials and Methods), hence there has been no attempt to interrogate the full record of dietary breadth and change for a globally distributed, omnivorous species, from the prehistoric to recent times. To address this gap, we collated isotope compositions of collagen as well as hair and nail keratin from three worldwide populations: modern urban (dates AD 1910 to 2020; Materials and Methods), modern subsistence (dates AD 1910 to 2020), and material dating to before the manufacture of industrial fertilizer (before AD 1910; pre-Haber-Bosch; hereafter, PHB). We calibrated all isotope compositions to their modern diet equivalent in order to directly compare modern and PHB distributions on a common scale. We show that the industrialized food system is vastly compressed in niche space and vastly less resilient compared with modern subsistence and PHB diets that are underpinned by complex food webs.

We systematically collated $(n=6,879)$ globally distributed analyses of PHB archaeological bone collagen (pre-1910), with the majority of the data derived from samples of mid-Holocene or later age. We further collated analyses from studies of modern (post-1910) hair and nail keratin from populations of subsistence foragers, fishers, agriculturalists and pastoralists $(n=1,167)$, and urban populations $(n=5,610)$. In order to compare populations, we adjusted all measured values onto a common frame of reference; this being the equivalent $\delta^{13} \mathrm{C}$ and $\delta^{15} \mathrm{~N}$ values of hair keratin in 2010 or modern keratin equivalent. We then used the accepted fractionations between human hair keratin and diet to calculate the modern diet equivalent $\left(\delta^{13} \mathrm{C}_{\mathrm{MDE}}\right.$ value) and $\left(\delta^{15} \mathrm{~N}_{\mathrm{MDE}}\right)$ values for all samples in 2010 (Materials and Methods).

This approach has the advantage of allowing direct comparison of all results against the framework of our much more detailed contemporary understanding of stable isotope systematics in the modern biosphere. Exploiting this link between PHB and modern samples requires the assumption that the environmental conditions that drive the food webs that humans rely upon, wherever they are, have remained stable and that the past can be mapped onto the present. While there have been changes in climate and environment during the Holocene, these have been relatively muted, with most larger-scale landscape change resulting from human intervention beginning at varying times across the world in the Holocene and accelerating rapidly with the rise of industrial agriculture in the 20th Century (22).

\section{Results}

Fig. 1 presents all modern and PHB data on the common dietary scale relative to 2010. The total range across all PHB samples for $\delta^{13} \mathrm{C}_{\mathrm{MDE}}$ value is -31.4 to $-10.4 \%$ and for $\delta^{15} \mathrm{~N}_{\mathrm{MDE}}$ value is -2.3 to $+22.3 \%$. Isotope values are not randomly distributed across the range of potential paired values, instead being concentrated in a rough trapezoid representing the full range of dietary possibilities available in PHB times. The stable isotope compositions of modern individuals living on a "traditional" subsistence diet are remarkably similar to the $\mathrm{PHB}$ range, with $\delta^{13} \mathrm{C}_{\mathrm{MDE}}$ values that range from -30.1 to $-11.7 \%$ and $\delta^{15} \mathrm{~N}_{\mathrm{MDE}}$ values from -1.8 to $+15.1 \%$. These values cover most - but not all—of the range covered by the PHB population even though the numbers of studies of "traditional" subsistence diet are far fewer $(n=12$ studies of 24 populations; Dataset S1), and large regions of the globe, particularly those most fertile, are no longer occupied by any individuals living by "traditional" subsistence means. By contrast, the modern urban population is highly compressed, with means for analyses grouped by countries for modern individuals living on a globalized diet ranging from $-24.2 \%$ [for the subset of vegans in the United Kingdom (23)] to $-18.7 \%$ [for the population sampled in Iran and Pakistan (18)] for $\delta^{13} C_{M D E}$ values. $\delta^{15} \mathrm{~N}_{\mathrm{MDE}}$ mean values range from $+0.45 \%$ [for the subset of vegans in Gothenberg, Germany (24)] to $+5.7 \%$ [Port Moresby, Papua New Guinea (25)]. The Papua New Guinea urban population is unique in the modern dataset for the maintenance of a close connection to subsistence foodstuffs compared with the other urban populations in the dataset.

\section{Discussion}

The outer trapezoid-shaped bounds in the relationship between $\delta^{13} \mathrm{C}_{\mathrm{MDE}}$ value and $\delta^{15} \mathrm{~N}_{\mathrm{MDE}}$ value in Fig. 1 are constrained fundamentally by the range of isotope compositions possible at the base of food webs globally (26). In the terrestrial biosphere, this range is driven primarily by the established relationships between climate and the $\delta^{13} \mathrm{C}_{\mathrm{MDE}}$ value and $\delta^{15} \mathrm{~N}_{\mathrm{MDE}}$ value of primary production (27-31). The climate-driven relationship is modulated regionally and locally by edaphic factors such as soil type (32) and in some cases by environment-specific phenomena such as the incorporation of low $\delta^{13} \mathrm{C}_{\mathrm{MDE}}$-value carbon from methane oxidation into some lacustrine and wetland food webs (33). In the ocean, $\delta^{13} \mathrm{C}_{\mathrm{MDE}}$ and $\delta^{15} \mathrm{~N}_{\mathrm{MDE}}$ values at the base of the food web also vary in broadly predictable ways, controlled primarily by global ocean circulation and productivity $(34,35)$, modulated at the local scale by interactions with the terrestrial biosphere, for example, through the incorporation of seabird guano into the base of local food webs $(36,37)$.

Additional to these fundamental controls on the stable isotope composition of primary production are local modifications possible through processes specific to particular environmental niches. These include trophic enrichment (TE) in both $\delta^{13} \mathrm{C}_{\mathrm{MDE}}$ and $\delta^{15} \mathrm{~N}_{\text {MDE }}$ values through complex food-web interactions $(26,38$, 39) conditioned ultimately by the choice between, and manipulation of, the dietary possibilities available to humans, in the context of societal and technological constraints and innovations (10, 40-42). The development of new subsistence strategies and pastoral/agricultural innovations $(43,44)$ including the domestication and expansion of new crops (45) vary widely in terms of both the time of initial introduction and the rate and extent of subsequent geographic spread (22). As a result of this, and regional differences in isotope baselines, we explicitly do not address regional trends in the PHB data over time, instead considering the data only in terms of the major environmental (climate) drivers of change in baseline isotope composition at the global scale.

At the global scale, all of the space within the outer bounds delineated by the range observed in primary production is occupied to a greater or lesser degree by the isotope composition of PHB humans, from single individuals to large populations of individuals. This is indicative of our impressive capacity for adaptive omnivory at the global scale. The observation that the results for modern individuals on a subsistence diet occupies much the same isotope space as the results for the (much larger) PHB sample group indicates that the conversion of all the results to a "modern" diet in 2010 has successfully enabled the comparison between PHB and modern human diet (Fig. 1).

The most striking difference across the entire dataset is the compressed range of modern nonsubsistence diets compared to modern subsistence and PHB isotope values. The $\delta^{15} \mathrm{~N}_{M D E}$ values of modern subsistence diets imply consumption across trophic levels from around one (plant only) to $\sim$ four to five in populations reliant dominantly on high latitude marine resources (e.g., Greenland), assuming an average trophic enrichment factor (TEF) of 4\%o (Materials and Methods). Some PHB populations appear to be consuming at even higher trophic levels, though the highest $\delta^{15} \mathrm{~N}_{\text {MDE }}$ values $>+15 \%$ relate to a possibly unique combination of high marine $\delta^{15} \mathrm{~N}$ values related to marine upwelling along an extremely arid coastline with a high-elevation hinterland in Peru and Chile, augmented by seabird guano fertilization of crops (46).

In contrast, comparison of the range of $\delta^{15} \mathrm{~N}$ values of identified vegans (Dataset S1) with the range of $\delta^{15} \mathrm{~N}$ values averaged 


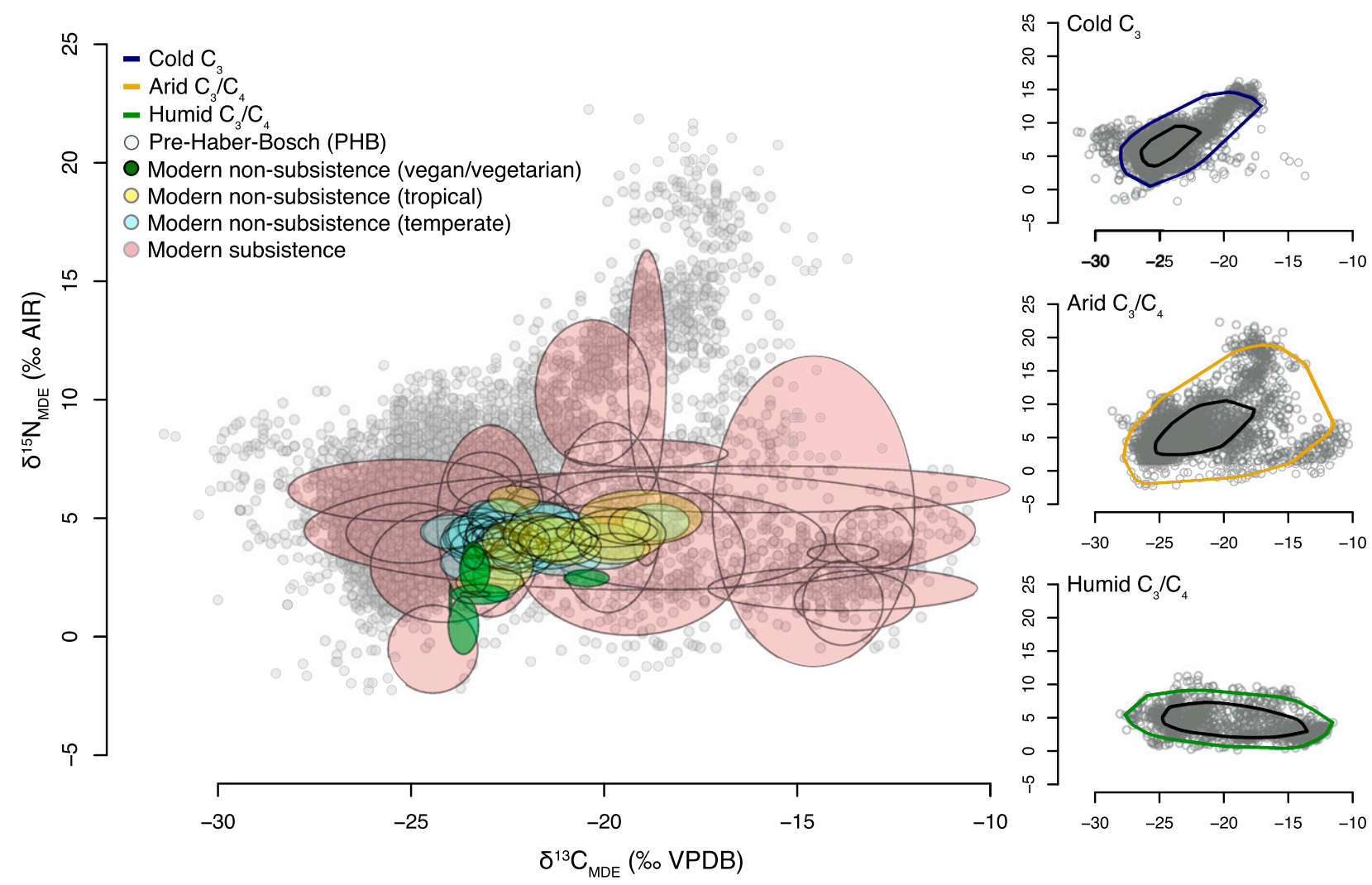

Fig. 1. (Main) $\delta^{13} \mathrm{C}_{\mathrm{MDE}}$ and $\delta^{15} \mathrm{~N}_{\mathrm{MDE}}$ of modern subsistence and nonsubsistence individuals plotted as ellipses representing the population $\mu$ (ellipse center) and $2 \sigma$ (ellipse extent). Vegans/vegetarians within the modern nonsubsistence category are highlighted by green-shaded ellipses. The modern nonsubsistence data are plotted on an expanded scale by region in SI Appendix, Fig. S1. (Side) Bagplots of $\delta^{13} \mathrm{C}_{\mathrm{MDE}}$ and $\delta^{15} \mathrm{~N}_{\mathrm{MDE}}$ pairs for PHB individuals (gray circles on the main panel) within cold $C_{3}$, arid $C_{3} / C 4$, and humid $C_{3} / C_{4}$ environments. Black contours enclose the central $50 \%$ of individuals, and colored contours enclose the central $95 \%$ of individuals. The modern nonsubsistence data are plotted on an expanded scale by region in SI Appendix, Fig. S1. Both PHB and modern subsistence data points are plotted in SI Appendix, Fig. S2. Isotope values are reported relative to the international reference scales of Air for nitrogen and Vienna PeeDee Belemnite (VPDB) for carbon.

by country indicates a mean difference of $+2.7 \%$ (range +0.5 to $+4.8 \%$ ) . Based on a TEF of $+4 \%$ and a vegan diet representing an "herbivore" trophic level of 2 (Materials and Methods), this implies a mean trophic level for modern omnivorous populations of 2.7 with a total range from 2.1 for India to 3.2 for urban Papua New Guinea. Global average human trophic level, as indicated by direct measures of diet, similarly aggregated by country, ranges from 2.0 to $2.6(7)$, in general agreement with the range implied by the nitrogen isotope approach used here. This trophic range is similar to the trophic level occupied by "anchovies or pigs" in a natural food web (7).

In part, the observed compression in the range of modern nonsubsistence populations is the result of improvement in diet in developing countries, such that trophic levels in developing countries have increased, thereby converging somewhat with those of developed countries over time (7). In part, the observed compression is the result of a general decrease in the trophic level of animal and fish resources extracted for consumption from natural food webs as a result of overexploitation in recent decades (47). However, the largest contribution to the apparent decrease in trophic level over the range observed in PHB populations is likely due to the disconnection of the majority of the modern human population from complex natural food webs and their replacement by the simpler food webs (48) and flatter food chains associated with industrial agriculture and pastoralism (49). This has effectively removed these other sources of trophic diversification from the human diet.
In the particular context of the natural nitrogen isotope cycle, modern industrial fertilizer produced from atmospheric nitrogen has a mean $\delta^{15} \mathrm{~N}$ value of $-0.2 \pm 2 \%$, whereas natural soils and fertilizers, depending on environment and source have mean $\delta^{15} \mathrm{~N}$ values that range up to $+7.1 \%$ (50). Industrial fertilizer use has increased rapidly since the 1960s, and global demand now exceeds $100 \mathrm{Tg}$ per year (51). This fertilizer is used in annual to subannual cycles of application and harvest, often in conjunction with irrigation in semiarid regions once limited to rainfed crop production. Industrial farming has therefore effectively "short-circuited" the suite of longer-term natural soil isotope fractionation processes leading to the higher soil $\delta^{15} \mathrm{~N}$ values that are ultimately reflected in human diets based on natural food webs. Thus, for example, modern human $\delta^{15} \mathrm{~N}_{\mathrm{MDE}}$ values from developed countries cover a similar range to the $\delta^{15} \mathrm{~N}_{\mathrm{MDE}}$ values of enslaved Africans in the Caribbean in the seventeenth to nineteenth centuries, whose diets were dominantly plant-based (52).

The equally dramatic compression in the range of modern $\delta^{13} \mathrm{C}_{\mathrm{MDE}}$ values in Fig. 1 is a direct consequence of globalization. Thus, $\mathrm{C}_{4}$ staples (e.g., sugar and maize-derived products) and $\mathrm{C}_{3}$ staples (e.g., wheat and rice) are now cultivated well outside of their natural range using irrigation and shipped across the world. The supermarkets that draw on these global supply chains now have a $>50 \%$ share of food retailing in countries with a $>$ US $\$ 10,000$ per capita annual income (53). While some regional differentiation between tropical and temperate countries remains in $\delta^{13} \mathrm{C}_{\mathrm{MDE}}$ values (Fig. 1 and SI Appendix, Fig. S1), the modern range in values 
has reduced to around one-third of that observed across the PHB world.

Given the primacy of climate as the major driver of the broadest global trends in the stable isotope composition of primary production, we identify three general PHB "environments" at the global scale (Fig. 1). The primary distinction is the separation of regions with an aridity index of $>0.5$ (subhumid to humid) from $<0.5$ (arid to hyperarid) (54). "Arid $\mathrm{C}_{3} / \mathrm{C}_{4}$ " environments span a wide range of temperatures and here include regions with a Mediterranean climate that experience significant seasonal water stress. Humid environments are separated into the warmer regions that potentially contain natural $\mathrm{C}_{4}$ biomass (humid $\mathrm{C}_{3} / \mathrm{C}_{4}$ ) and colder regions that contain only $\mathrm{C}_{3}$ biomass ( cold $\mathrm{C}_{3}$ ), based on the modern distribution of $\mathrm{C}_{4}$ biomass (28). Across all three categories, some PHB populations also had a variable degree of access to marine and/or freshwater aquatic resources with a stable isotope composition often distinct from local terrestrial resources $(10,14,38)$.

The vast majority of $\mathrm{PHB}$ results from regions where $\mathrm{C}_{4}$ vegetation does not naturally occur plot along a broad diagonal from terrestrial $\delta^{13} \mathrm{C}_{\mathrm{MDE}}$ values of -25 to $-28 \%$ and $\delta^{15} \mathrm{~N}_{\mathrm{MDE}}$ values below $+10 \%$ (e.g., Western Europe) toward a progressively more marine-influenced diet indicated by $\delta^{13} \mathrm{C}_{\mathrm{MDE}}$ values of $>-20 \%$ and $\delta^{15} \mathrm{~N}_{\mathrm{MDE}}$ values $>+10 \%$ (e.g., Greenland and Alaska). At $\delta^{15} \mathrm{~N}$ values $<10 \%$, $\delta{ }^{13} \mathrm{C}_{\mathrm{MDE}}$ values up to $\sim-23 \%$ o can still indicate a purely $\mathrm{C}_{3}$ diet influenced by combinations of $\mathrm{TE}$ as a result of meat consumption and the adoption of agricultural innovations such as manuring $(43,55,56)$ along with natural variations in discrimination by $\mathrm{C}_{3}$ plants, particularly between trees (forest) and $\mathrm{C}_{3}$ grasses (pasture) and associated with climate, soil type $(32,57)$, and land use $(58)$. The scatter of points to higher $\delta^{13} \mathrm{C}_{\mathrm{MDE}}$ values $>\sim-23 \%$ with relatively low $\delta^{15} \mathrm{~N}_{\mathrm{MDE}}$ values reflect a variable degree of consumption of introduced $\mathrm{C}_{4}$ crops such as millet in prehistory (45), particularly in Eastern Europe and the Caucasus as well as individuals migrating from locations with a $\mathrm{C}_{4}$ component in the diet in the last few centuries.

The $\mathrm{PHB}$ results for the humid $\mathrm{C}_{3} / \mathrm{C}_{4}$ grouping scatter over a relatively narrower range of $\delta^{15} \mathrm{~N}_{\mathrm{MDE}}$ values between 0 and $+10 \%$ o but span a wide range from purely $\mathrm{C}_{3}$ (southern Japan and eastern United States), to almost exclusively $\mathrm{C}_{4}$ (southern China and Mexico). The reliance on millet ( $\mathrm{a}_{4}$ crop) in China is evident in the concentration of analyses with $\delta^{13} \mathrm{C}_{\mathrm{MDE}}$ values above $-15 \%$ o and $\delta^{15} \mathrm{~N}_{\mathrm{MDE}}$ values below $+5 \%$. The data for the humid $\mathrm{C}_{3} / \mathrm{C}_{4}$ grouping as a whole implies that diet across this global range is within a maximum of 3.5 isotope-calculated trophic levels. This is consistent with modern subsistence diets from populations in the environments represented in this category from the Amazon (mixed plant- and fish-based diets) to Africa (mixed plant and meat). The grouping also includes island populations in the Pacific Ocean indicating that it is not possible to differentiate a marine from a purely terrestrial diet in the absence of other evidence.

The arid $\mathrm{C}_{3} / \mathrm{C}_{4}$ grouping covers the entire $\delta^{13} \mathrm{C}_{\mathrm{MDE}}$ isotope dietary space from exclusively $\mathrm{C}_{3}$ plant based (e.g., montane central United States) to largely $\mathrm{C}_{4}$ based (e.g., central Chile). In

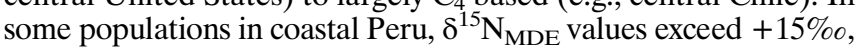
but these very high values have been attributed to the addition of seabird guano fertilizer to crops (46). For coastal populations, the utilization of marine resources may explain the extension to higher $\delta^{15} \mathrm{~N}_{\mathrm{MDE}}$ values compared to the humid $\mathrm{C}_{3} / \mathrm{C}_{4}$ grouping. For populations in more arid environments, it is likely that the increase in plant $\delta^{15} \mathrm{~N}_{\mathrm{MDE}}$ values generally observed in arid environments is a contributing factor to the comparatively high $\delta^{15} \mathrm{~N}_{M D E}$ values observed in many samples in this group. In addition, it may be that in particularly hyperarid environments such as montane central Peru, where plant biomass is not an abundant resource, populations relied to a greater extent on higher-trophic-level animal resources (e.g., rodents, reptiles, and birds) for dietary protein.
As with the humid $\mathrm{C}_{3} / \mathrm{C}_{4}$ grouping, it is not possible to uniquely identify an aquatic component to diet across much of the arid $\mathrm{C}_{3} / \mathrm{C}_{4}$ range in the absence of other information.

The approach adopted here, represented conceptually in Fig. 2, moves from a local archaeological framing, where interest is primarily in the proportion of potential food items in the diet of PHB individuals in that area, to a global context where humans can be placed in an ecological framework as part of, but increasingly able to manipulate, complex natural food webs. A growing body of anthropological research also examines the human place in food webs worldwide. Humans have been shown, through their hyperomnivory and prey-switching ability, to have consumed a wider variety of organisms than any other taxon in their respective systems $(4,59)$. Modeled food webs that include humans indicate the aggregate trophic position of humans ranges from up to $\sim 5$ for offshore food webs in the Aleutian Islands (4) to $~ 2.3$ for modern Indigenous populations in the deserts of Western Australia (59). These trophic positions were both determined using the shortweighted trophic level calculation, which allows an estimate of feeding strength from binary interactions within modeled food webs (60). The compilation of full ecologically realistic model trophic webs is laborious and therefore there are few available. However, the broad comparability of the short-weighted trophic level inferences drawn from the modeling approach, with the isotope approach presented here, is encouraging.

Thus, it becomes possible to conceive of the stable isotope composition of archaeological remains as an integrated signal of global human utilization and manipulation of local food webs $(59,61)$. Recasting the archaeological results into their modern diet equivalent composition allows comparison with the much larger and more detailed datasets available for plants and fauna in modern ecosystems (Fig. 2), thereby increasing interpretive power through enabling the development of location-specific isotope baselines (e.g., ref. 13). Even in temperate, humid $\mathrm{C}_{3}$-dominated regions, microclimatic and edaphic factors mean that baseline isotope compositions for both carbon and nitrogen often vary by 2 to $3 \%$ over tens to hundreds of kilometers $(13,62,63)$ with a larger range of variation globally. The isotope signal associated with the adoption of $\mathrm{C}_{4}$ crops is sufficiently large in comparison to baseline variation to track at a continental scale (e.g., ref. 45). Multiple other cultural and technological innovations that have been shown to impact human diet over time $(43,44)$ result in changes in isotope composition of the same magnitude as natural variability in local isotope baselines. Therefore, a limitation of this study is that a global temporal comparison of dietary change in ancient populations is not possible, as it requires a finer-grained, spatially explicit (isoscape) understanding of variability in isotope baselines in relation to climatic, microclimatic, and edaphic variables than is presently available (64).

Human populations in prehistory bolstered their resilience by being able to prey switch within complex natural food webs (61) Comparison of the PHB, modern subsistence, and modern urbanized isotope results presented here suggest that modern human food webs have become dramatically compressed as a result of the ongoing expansion of industrial agriculture and pastoralism at the expense of natural ecosystems. In turn, this is resulting in a cascade of "rewiring" to remaining natural terrestrial and marine food webs globally (65) that can reduce the complexity, and therefore the resilience, of global ecosystems in the face of accelerating environmental change $(47-49,66)$.

\section{Materials and Methods}

We collated published individual stable isotope analyses of archaeological human bone collagen with a focus on as wide a geographic coverage as possible (Dataset S1). Studies were identified from a systematic search of Google Scholar using combinations of the search terms including isotope, collagen, keratin, diet, ancient, and archaeology along with regional and country keywords. Not all literature thus identified was available to us, and 


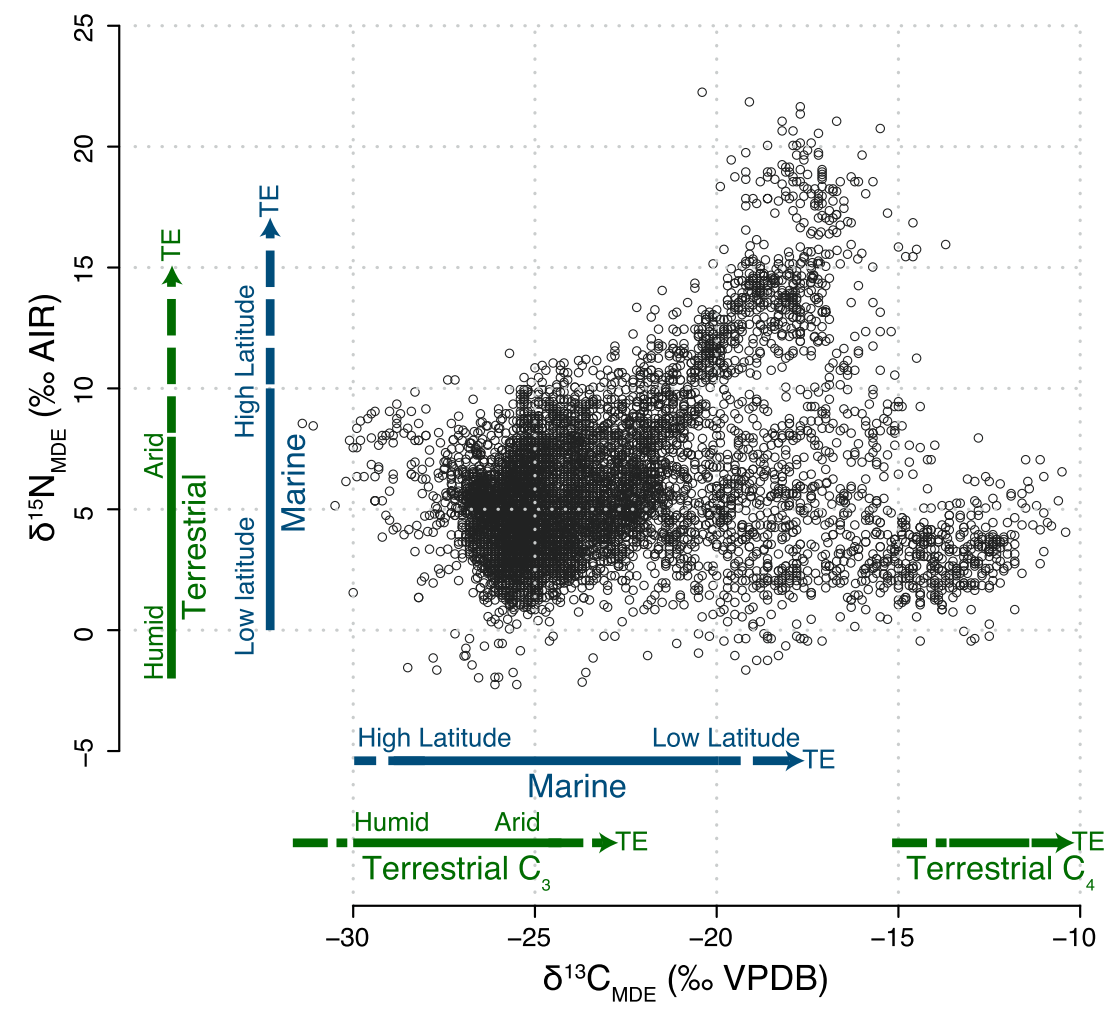

Fig. 2. Modern diet equivalent data for all PHB individuals (gray points) representing the full dietary spectrum. Terrestrial (green) and Marine (blue) plant/ animal $\delta^{13} \mathrm{C}_{\mathrm{MDE}}$ and $\delta^{15} \mathrm{~N}_{\mathrm{MDE}}$ ranges are given (solid lines) for comparison. Dashed arrows indicate where tropic enrichment (TE) extends this range to higher values. The marine range for primary production taken from ref. 34 for nitrogen and ref. 35 for carbon. The terrestrial range of values for primary production are also shown for carbon $(29,30,32,72)$ and for nitrogen $(27,29,31)$.

studies where primary data were not presented in the paper or supplementary information were also excluded. The compilation is therefore incomplete but, more importantly, is globally representative. From the total database, we removed analyses of infant bone material, where identified, due to apparent TE associated with breastfeeding (67) and also removed analyses outside the recommended range of $\mathrm{C}: \mathrm{N}$ ratios for collagen (9), where reported (2.9 to 3.6). We did not further interrogate the techniques or instrumentation used to perform the analyses.

We further collated modern analyses of hair and nail keratin from 10 studies of populations still living a mostly traditional subsistence lifestyle and included one study that only provided means plus SDs because it provided data ( $n=123$ analyses) on an additional 15 globally distributed populations (68) We drew on an existing global synthesis of hair stable isotope composition from nonsubsistence populations, aggregated by country (18), augmented with data from more recent studies (Dataset S1). As the modern nonsubsistence dataset is not available as individual analyses, we report these as country means with $95 \%$ $\mathrm{Cl}$. We take the boundary between "archaeological" and "modern" to be 1910 the date at which large scale production of nitrogen fertilizer by the HaberBosch process became possible, underpinning the rise of industrial agriculture in the 20th century. Samples from before 1910 we term PHB.

The $\delta^{13} \mathrm{C}$ and $\delta^{15} \mathrm{~N}$ values of all human tissues, including collagen and keratin, are modified to varying degrees from that of the diet by a number of physiological processes (15-18), such that bone collagen and hair and nail keratin produced by an individual from the same diet do not have the same stable isotope composition. We therefore adjusted all analyses to their equivalent hair-keratin isotope value using published fractionation factors. The fractionation factors applied are provided in Dataset S1, and while these are uncertain, generally by $<0.5 \%$, they are simple additions/subtractions uniformly applied across all data that can be amended if more precise data become available.

The $\delta^{13} \mathrm{C}$ value of all human tissues is ultimately also dependent on the $\delta^{13} \mathrm{C}$ value of atmospheric $\mathrm{CO}_{2}$ at the time it was assimilated by photosynthesis. While the $\delta^{13} \mathrm{C}$ value of the atmosphere was relatively constant through most of the Holocene [-6.4 $\pm 0.05 \%$ (6)], it decreased throughout the 20th century due to fossil fuel combustion [to $-8.3 \%$ in 2010 (69)]. As the majority of the modern samples analyzed were collected in the last two decades, we take 2010 as the central reference year and adjust the $\delta^{13} \mathrm{C}$ value of all PHB samples to their equivalent value in that year. Uncertainty around when some modern samples were actually collected results in an additional uncertainty of $\pm \sim 0.2$ to $0.3 \%$ in cases where samples were collected either very recently or in the last decade of the 20th century, and for one study that used hair collected in the 1930s to 1950s, we adjusted the atmospheric correction by $0.6 \%$ (68). The approach adopted above places all data into a directly comparable reference frame. We then used accepted fractionation factors between hair keratin and diet (Dataset S1) to present all data as modern diet equivalent isotope values $\left(\delta^{13} C_{M D E}\right.$ and $\delta^{15} \mathrm{~N}_{\text {MDE }}$ values). For convenience, we also present all carbon isotope data as diet adjusted to preindustrial diet equivalent $\mathrm{CO}_{2} \delta^{13} \mathrm{C}$ values $\left(\delta^{13} \mathrm{C}_{\mathrm{PDE}}\right.$; Dataset $\left.\mathrm{S} 1\right)$.

The final PHB dataset consists of 6,879 entries. Of these, we have classified 2,973 as "Arid $C_{3} / C_{4}$," 2,655 as "Cold $C_{3}$ only," and 1,251 as "Humid $C_{3} / C_{4}$." Given the large size of the dataset, bag plots or modified bivariate boxplots (Fig. 1) were constructed to visualize the data distribution by way of its halfspace depth or Tukey depth (70). In this, the "bag" encloses the central $50 \%$ of the data points (black contour) while the modified "loop" (colored contours) encloses $95 \%$ of the points, allowing for the quick identification of the location and spread of the data cloud.

Trophic level is usually defined by nitrogen isotope composition and is calculated using the following equation:

$$
T E=\frac{\delta^{15} N_{\text {consumer }}-\delta^{15} N_{\text {producer }}}{T E F}+1 .
$$

Where TE is trophic enrichment and TEF is trophic enrichment factor, $\delta{ }^{15} N_{\text {consumer }}$ and $\delta^{15} N_{\text {producer }}$ are the stable values of the consumer organism, and the organism being consumed, respectively. Published TEF range between approximately +3 and $+5 \%$, and here we assume a value of $+4 \% 0(10,71)$.

Data Availability. All study data are included in the article and/or supporting information.

ACKNOWLEDGMENTS. This research was undertaken by the Australian Research Council Centre of Excellence for Australian Biodiversity and Heritage (CE170100015). 
1. S. Marciniak, G. H. Perry, Harnessing ancient genomes to study the history of human adaptation. Nat. Rev. Genet. 18, 659-674 (2017).

2. S. A. Crabtree, J. A. Dunne, S. N. Wood, Ecological networks and archaeology. An tiquity. https://doi.org/10.15184/aqy.2021.38.

3. P. D. Roopnarine, Humans are apex predators. Proc. Natl. Acad. Sci. U.S.A. 111, E796 (2014)

4. J. A. Dunne et al., The roles and impacts of human hunter-gatherers in North Pacific marine food webs. Sci. Rep. 6, 21179 (2016).

5. K. N. Laland, M. J. O'Brien, Niche construction theory and archaeology. J. Archaeol. Method Theory 17, 303-322 (2010).

6. J. Schmitt et al., Carbon isotope constraints on the deglacial $\mathrm{CO}_{2}$ rise from ice cores. Science 336, 711-714 (2012).

7. S. Bonhommeau et al., Eating up the world's food web and the human trophic level. Proc. Natl. Acad. Sci. U.S.A. 110, 20617-20620 (2013).

8. M. J. Schoeninger, K. Moore, Bone stable isotope studies in archaeology. J. World Prehist. 6, 247-296 (1992).

9. M. J. DeNiro, Postmortem preservation and alteration of in vivo bone collagen isotope ratios in relation to palaeodietary reconstruction. Nature 317, 806-809 (1985).

10. R. E. M. Hedges, L. M. Reynard, Nitrogen isotopes and the trophic level of humans in archaeology. J. Archaeol. Sci. 34, 1240-1251 (2007).

11. D. C. Salazar-García, A. Romero, P. García-Borja, M. E. Subirà, M. P. Richards, A combined dietary approach using isotope and dental buccal-microwear analysis of human remain from the Neolithic, Roman and Medieval periods from the archaeological site of Tossal de les Basses (Alicante, Spain). J. Archaeol. Sci. Rep. 6, 610-619 (2016).

12. G. Goude, M. Fontugne, Carbon and nitrogen isotopic variability in bone collagen during the Neolithic period: Influence of environmental factors and diet. J. Archaeol. Sci. 70, 117-131 (2016)

13. G. Barrientos, L. Catella, N. S. Morales, A journey into the landscape of past feeding habits: Mapping geographic variations in the isotope $\left(\delta^{15} \mathrm{~N}\right)$-inferred trophic position of prehistoric human populations. Quat. Int. 548, 13-26 (2020).

14. E. Guiry, Complexities of stable carbon and nitrogen isotope biogeochemistry in ancient freshwater ecosystems: Implications for the study of past subsistence and environmental change. Front. Ecol. Evol. 7, 313 (2019).

15. T. C. O'Connell, R. E. M. Hedges, Investigations into the effect of diet on modern human hair isotopic values. Am. J. Phys. Anthropol. 108, 409-425 (1999).

16. C. Lehn, E. Mützel, A. Rossmann, Multi-element stable isotope analysis of $H, C, N$ and $S$ in hair and nails of contemporary human remains. Int. J. Legal Med. 125, 695-706 (2011).

17. T. C. O'Connell, C. J. Kneale, N. Tasevska, G. G. C. Kuhnle, The diet-body offset in human nitrogen isotopic values: A controlled dietary study. Am. J. Phys. Anthropol. 149, 426-434 (2012).

18. F. Hülsemann et al., Global spatial distributions of nitrogen and carbon stable isotope ratios of modern human hair. Rapid Commun. Mass Spectrom. 29, 2111-2121 (2015).

19. L. M. Reynard, N. Burt, H. E. C. Koon, N. Tuross, Limits and possibilities in the geolocation of humans using multiple isotope ratios $(\mathrm{H}, \mathrm{O}, \mathrm{N}, \mathrm{C})$ of hair from east coast cities of the USA. Isotopes Environ. Health Stud. 52, 498-512 (2016).

20. E. J. Bartelink, G. E. Berg, M. M. Beasley, L. A. Chesson, Application of stable isotope forensics for predicting region of origin of human remains from past wars and conflicts: Human remains from past wars and conflicts. Ann. Anthropol. Pract. 38, 124-136 (2014)

21. L. O. Valenzuela, L. A. Chesson, S. P. O'Grady, T. E. Cerling, J. R. Ehleringer, Spatial distributions of carbon, nitrogen and sulfur isotope ratios in human hair across the central United States. Rapid Commun. Mass Spectrom. 25, 861-868 (2011).

22. L. Stephens et al., Archaeological assessment reveals Earth's early transformation through land use. Science 365, 897-902 (2019)

23. R. Bol, C. Pflieger, Stable isotope $\left({ }^{13} \mathrm{C},{ }^{15} \mathrm{~N}\right.$ and $\left.{ }^{34} \mathrm{~S}\right)$ analysis of the hair of modern human and their domestic animals. Rapid Commun. Mass Spectrom. 16, 2195-2200 (2002).

24. L. Ellegård et al., Distinguishing vegan-, vegetarian-, and omnivorous diets by hair isotopic analysis. Clin. Nutr. 38, 2949-2951 (2019).

25. M. Umezaki et al., Association between sex inequality in animal protein intake and economic development in the Papua New Guinea highlands: The carbon and nitrogen isotopic composition of scalp hair and fingernail. Am. J. Phys. Anthropol. 159, 164-173 (2016).

26. M. M. Casey, D. M. Post, The problem of isotopic baseline: Reconstructing the diet and trophic position of fossil animals. Earth Sci. Rev. 106, 131-148 (2011)

27. L. L. Handley et al., The $15 \mathrm{~N}$ natural abundance $\left(\delta^{15} \mathrm{~N}\right)$ of ecosystem samples reflects measures of water availability. Funct. Plant Biol. 26, 185-199 (1999).

28. C. J. Still, J. A. Berry, G. J. Collatz, R. S. DeFries, Global distribution of C3 and C4 vegetation: Carbon cycle implications. Glob. Biogeochem. Cycles 17, 6-1-6-14 (2003).

29. B. P. Murphy, D. M. J. S. Bowman, The carbon and nitrogen isotope composition of Australian grasses in relation to climate: Carbon and nitrogen isotopes in grasses. Funct. Ecol. 23, 1040-1049 (2009)

30. M. J. Kohn, Carbon isotope compositions of terrestrial $C_{3}$ plants as indicators of (paleo) ecology and (paleo)climate. Proc. Natl. Acad. Sci. U.S.A. 107, 19691-19695 (2010).

31. J. M. Craine et al., Ecological interpretations of nitrogen isotope ratios of terrestria plants and soils. Plant Soil 396, 1-26 (2015).

32. W. K. Cornwell et al., Climate and soils together regulate photosynthetic carbon isotope discrimination within $C_{3}$ plants worldwide. Glob. Ecol. Biogeogr. 27, 1056-1067 (2018)

33. A. M. Sanseverino, D. Bastviken, I. Sundh, J. Pickova, A. Enrich-Prast, Methane carbon supports aquatic food webs to the fish level. PLoS One 7, e42723 (2012).

34. B. S. Graham, P. L. Koch, S. D. Newsome, K. W. McMahon, D. Aurioles, "Using isoscapes to trace the movements and foraging behavior of top predators in oceanic ecosystems" in Isoscapes, J. B. West, G. J. Bowen, T. E. Dawson, K. P. Tu, Eds. (Springer Netherlands, 2010), pp. 299-318.

35. S. Magozzi, A. Yool, H. B. Vander Zanden, M. B. Wunder, C. N. Trueman, Using ocean models to predict spatial and temporal variation in marine carbon isotopes. Ecosphere 8, e01763 (2017)

36. S. C. Wainright, J. C. Haney, C. Kerr, A. N. Golovkin, M. V. Flint, Utilization of nitrogen derived from seabird guano by terrestrial and marine plants at St. Paul, Pribilof Islands, Bering Sea, Alaska. Mar. Biol. 131, 63-71 (1998).
37. F. Santana-Sagredo, et al., 'White gold' guano fertilizer drove agricultural intensification in the Atacama Desert from AD 1000. Nat. Plants 7, 152-158 (2021).

38. M. J. V. Zanden, J. B. Rasmussen, Variation in $\delta^{15} \mathrm{~N}$ and $\delta^{13} \mathrm{C}$ trophic fractionation: Implications for aquatic food web studies. Limnol. Oceanogr. 46, 2061-2066 (2001)

39. C. A. Layman et al., Applying stable isotopes to examine food-web structure: An overview of analytical tools. Biol. Rev. Camb. Philos. Soc. 87, 545-562 (2012)

40. P. Szpak, Complexities of nitrogen isotope biogeochemistry in plant-soil systems: Implications for the study of ancient agricultural and animal management practices. Front. Plant Sci. 5, 288 (2014).

41. A. L. Lamb, J. E. Evans, R. Buckley, J. Appleby, Multi-isotope analysis demonstrates significant lifestyle changes in King Richard III. J. Archaeol. Sci. 50, 559-565 (2014).

42. J. Jones, K. Britton, Multi-scale, integrated approaches to understanding the nature and impact of past environmental and climatic change in the archaeological record, and the role of isotope zooarchaeology. J. Archaeol. Sci. Rep. 23, 968-972 (2019).

43. K. J. Gron et al., Archaeological cereals as an isotope record of long-term soil health and anthropogenic amendment in southern Scandinavia. Quat. Sci. Rev. 253, 106762 (2021).

44. D. R. Gröcke, E. R. Treasure, J. J. Lester, K. J. Gron, M. J. Church, Effects of marine biofertilisation on Celtic bean carbon, nitrogen and sulphur isotopes: Implications for reconstructing past diet and farming practices. Rapid Commun. Mass Spectrom. 35, e8985 (2021).

45. T. Wang et al., Tianshanbeilu and the isotopic millet road: Reviewing the late Neolithic/Bronze age radiation of human millet consumption from north China to Europe. Natl. Sci. Rev. 6, 1024-1039 (2019).

46. P. Szpak, J.-F. Millaire, C. D. White, F. J. Longstaffe, Influence of seabird guano and camelid dung fertilization on the nitrogen isotopic composition of field-grown maize (Zea mays). J. Archaeol. Sci. 39, 3721-3740 (2012).

47. T. E. Essington, A. H. Beaudreau, J. Wiedenmann, Fishing through marine food webs Proc. Natl. Acad. Sci. U.S.A. 103, 3171-3175 (2006)

48. M. A. Tsiafouli et al., Intensive agriculture reduces soil biodiversity across Europe. Glob. Change Biol. 21, 973-985 (2015).

49. R. H. Heleno, W. J. Ripple, A. Traveset, Scientists' warning on endangered food webs. Web Ecol. 20, 1-10 (2020)

50. A. S. Bateman, S. D. Kelly, Fertilizer nitrogen isotope signatures. Isotopes Environ Health Stud. 43, 237-247 (2007)

51. C. Lu, H. Tian, Global nitrogen and phosphorus fertilizer use for agriculture produc tion in the past half century: Shifted hot spots and nutrient imbalance. Earth Syst. Sci. Data 9, 181-192 (2017).

52. H. Schroeder, T. C. O'Connell, J. A. Evans, K. A. Shuler, R. E. M. Hedges, Trans-Atlantic slavery: Isotopic evidence for forced migration to Barbados. Am. J. Phys. Anthropol. 139, 547-557 (2009).

53. M. Qaim, Globalisation of agrifood systems and sustainable nutrition. Proc. Nutr. Soc. 76, 12-21 (2017)

54. J. Spinoni, J. Vogt, G. Naumann, H. Carrao, P. Barbosa, Towards identifying areas at climatological risk of desertification using the Köppen-Geiger classification and FAO aridity index: Towards identifying areas at climatological risk of desertification. Int J. Climatol. 35, 2210-2222 (2015).

55. R. Bol et al., The natural abundance of ${ }^{13} \mathrm{C},{ }^{15} \mathrm{~N},{ }^{34} \mathrm{~S}$ and ${ }^{14} \mathrm{C}$ in archived (1923-2000) plant and soil samples from the Askov long-term experiments on animal manure and mineral fertilizer. Rapid Commun. Mass Spectrom. 19, 3216-3226 (2005)

56. A. Bogaard, T. H. E. Heaton, P. Poulton, I. Merbach, The impact of manuring on nitrogen isotope ratios in cereals: Archaeological implications for reconstruction of diet and crop management practices. J. Archaeol. Sci. 34, 335-343 (2007)

57. R. E. Stevens, A. M. Lister, R. E. M. Hedges, Predicting diet, trophic level and palaeoecology from bone stable isotope analysis: A comparative study of five red dee populations. Oecologia 149, 12-21 (2006).

58. T. Doppler et al., Landscape opening and herding strategies: Carbon isotope analyses of herbivore bone collagen from the Neolithic and Bronze Age lakeshore site of Zurich-Mozartstrasse, Switzerland. Quat. Int. 436, 18-28 (2017).

59. S. A. Crabtree, D. W. Bird, R. B. Bird, Subsistence transitions and the simplification of ecological networks in the western desert of Australia. Hum. Ecol. 47, 165-177 (2019).

60. R. J. Williams, N. D. Martinez, Limits to trophic levels and omnivory in complex food webs: Theory and data. Am. Nat. 163, 458-468 (2004).

61. S. A. Crabtree, L. J. S. Vaughn, N. T. Crabtree, Reconstructing ancestral pueblo food webs in the southwestern United States. J. Archaeol. Sci. 81, 116-127 (2017).

62. B. Thornton et al., Distributions of carbon and nitrogen isotopes in Scotland's topsoil: A national-scale study: Stable isotopes in Scotland's topsoil. Eur. J. Soil Sci. 66, 1002-1011 (2015).

63. E. Hofman-Kamińska, H. Bocherens, T. Borowik, D. G. Drucker, R. Kowalczyk, Stable isotop signatures of large herbivore foraging habitats across Europe. PLoS One 13, e0190723 (2018).

64. J. N. Pauli et al., Opinion: Why we need a centralized repository for isotopic data. Proc. Natl. Acad. Sci. U.S.A. 114, 2997-3001 (2017).

65. T. J. Bartley et al., Food web rewiring in a changing world. Nat. Ecol. Evol. 3, 345-354 (2019).

66. T. N. Romanuk, Y. Zhou, F. S. Valdovinos, N. D. Martinez, Robustness trade-offs in model food webs. Adv. Ecol. Res. 56, 263-291 (2017)

67. L. M. Reynard, N. Tuross, The known, the unknown and the unknowable: Weaning times from archaeological bones using nitrogen isotope ratios. J. Archaeol. Sci. 53, 618-625 (2015).

68. G. J. Bowen et al., Dietary and physiological controls on the hydrogen and oxygen isotope ratios of hair from mid-20th century indigenous populations. Am. J. Phys. Anthropol. 139, 494-504 (2009).

69. H. Graven et al., Compiled records of carbon isotopes in atmospheric $\mathrm{CO}_{2}$ for historical simulations in CMIP6. Geosci. Model Dev. 10, 4405-4417 (2017)

70. P. J. Rousseeuw, I. Ruts, J. W. Tukey, The Bagplot: A bivariate boxplot. Am. Stat. 53, 382-387 (1999)

71. H. Bocherens, D. Drucker, Trophic level isotopic enrichment of carbon and nitrogen in bone collagen: Case studies from recent and ancient terrestrial ecosystems. Int J. Osteoarchaeol. 13, 46-53 (2003).

72. T. E. Cerling et al., Global vegetation change through the Miocene/Pliocene boundary. Nature 389, 153-158 (1997). 